\title{
The Five Design Educational Modules on Sinology and Their Significance and Construction
}

\author{
Zhu Ningjia \\ Design School \\ Jiaxing University \\ Jiaxing, China \\ ningjia2046@163.com
}

\author{
Heng Wu \\ Computer Science School \\ Texas Tech University \\ Lubbock, USA \\ cn_wuheng@163.com
}

\begin{abstract}
Given the impact that nationality and locality have on the essential elements of design, it is a demanding task for Chinese design education to develop new modules on design with Chinese style. In this paper, the five design educational modules on sinology, i.e. "the art of $\mathbf{L i}$ ", "the art of ink painting", "the art of poetry", "the art of war" and "the art of Zen", is proposed as a set of flexible curriculum framework that can be applied to modern design and contributes to the design-oriented quality education.
\end{abstract}

Keywords—design education; modules; sinology; curriculum

\section{INTRODUCTION}

Sinology is the study of Chinese language, literature, and history, which was generally seen as meaning "Chinese philology". The rise of Confucianism fever has made Sinology education attract more public attention. Sinology education are conducive to the building of national confidence, strengthening of national cohesion, and the improvement of harmonious social development, especially to the cultivation of university students' humanity spirit and full enhancement of their overall quality [1]. The cultural and national values should be embedded into "Chinese Design" and expanded more developing space by flexible application of sinology.

\section{SignifiCANCE OF THE DESIGN EdUCATIONAL MODULE ON SINOLOGY}

The appropriate combination between sinology education and ideological and cultural education is worth of attention and discussion. Design education is no exception. The significance of the design educational module on sinology is specified for four reasons: (1) responsibility for cultivation of students with improved humanity qualities by making in-depth reform of curriculum and innovating teaching programs during deepening the development of design education[2], (2)inheriting the Chinese traditional culture and wisdom, and improving the humanistic quality and comprehensive learning ability to solve the dilemma of contemporary Chinese spirit and culture, (3)breakthrough or supplement of the mainstream design education of Bauhaus with a deep understanding of the localization design, (4) thoughtful designers training with an international perspective and national identity to satisfy the needs of the rapid development of China's cultural and creative industries, (5) resources of a large number of eastern cultural wisdom and philosophy for design, conversely, the establishment of "life sinology" concept with the practical design application of sinology for the daily life experience[3].

\section{Five Modules ON SinOLOGY}

Five elements of sinology are be considered as the most suitable ideas and methods for building the systematic and comprehensive design educational modules after analyzing their contents and thinking characteristics respectively, and the relationship with design and their application on contemporary design as well, i.e. "the art of Li", "the art of ink painting", "the art of poetry", "the art of war" and "the art of Zen".

\section{A. The art of $L i$}

The art of Li(Rites) is in the top of the Six Arts of ancient China. Confucius described $\mathrm{Li}$ as all traditional forms that provided a standard of conduct. As a core text of the Confucian canon, the Book of Rites ( Liji), along with the Rites of Zhou and the Book of Etiquette and Rites, which are together known as the "Three $\mathrm{Li}$," is a collection of texts describing the social forms, administration, and ceremonial rites in ancient China[4]. The educational module of "The art of $\mathrm{Li}^{\prime}$ is to review elegant language and behavior paradigm by studying "Three $\mathrm{Li}$ " and to dissolve in words and deeds, result in advanced level of sense and heart of respect to things. Meanwhile, in terms of design itself, Chinese classical creation culture featured on designing object and its use ritual as a whole, e.g. tea ceremonies. Fig.1 shows a tableware ceremony set designed with decorative door god symbol for Chinese spring festival and chopsticks ritual with a chopstick groove ahead of the tray.

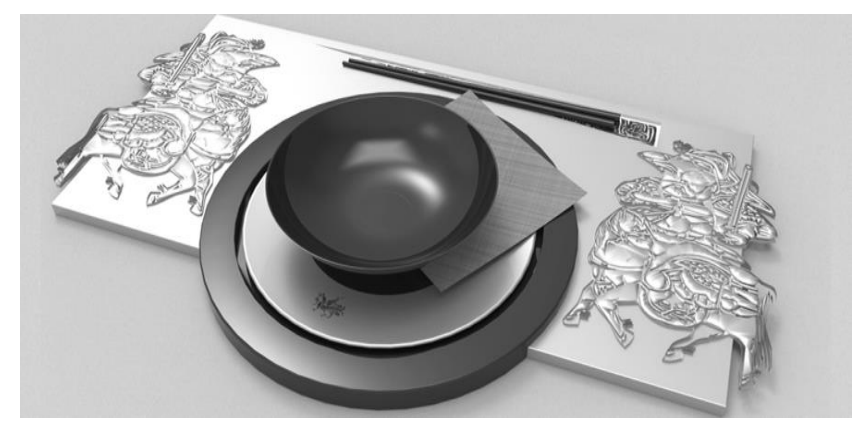

Fig.1. a tableware ceremony set design. 


\section{B. The art of ink painting}

Chinese ink painting art is one of the most unique art of thinking and the most characteristic of Chinese context. The International Ink Painting Biennial of Shenzhen, aiming at contemporary phase of the ink art and new media with traditional thought, shows many remarkable different styles of ink paintings such as the ink texture ceramic tile and freehand still life painting in Fig.2. Which are the key contents in basic curriculum of design[5]. More importantly, in view of its high generalization characteristics the art of Chinese ink painting is suitable for the training of the outline thinking and overall viewpoint such as the product modeling analysis, as shown in Fig.3.
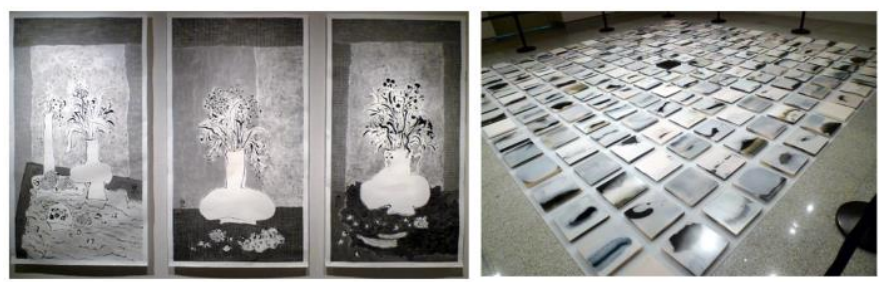

Fig.2. two contemporary Chinese ink painting works

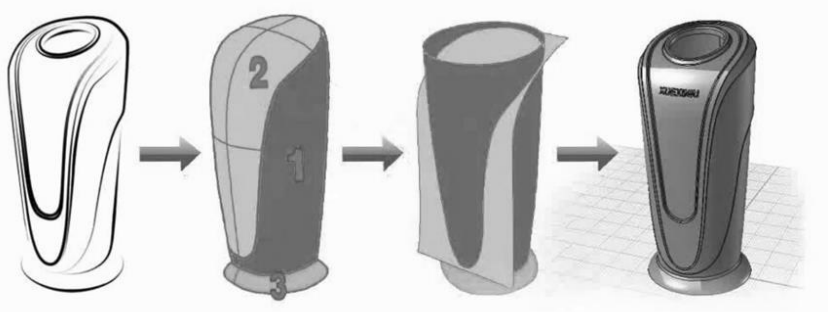

Fig.3. two contemporary Chinese ink painting works

\section{The art of poetry}

The generative process of design art depends on the symbol of its aesthetic conception that can be extracted from the Chinese classic poetry to trigger the emotion and interaction between the design and the user, especially in terms of indigenization and contextualized. It usually apply the artistic elements of the poetry into the visual expression and an poetic space around the theme in landscape creation as shown in Fig.4, where the inspiration of the thatched cottage design came from Du Fu`s poetry "My Thatched Cottage Was Broken by the West Wind".

\section{The art of war}

Design and business strategy teach students not only how to create innovative products, services, and policy, but also how to help organizations develop new business models for the future. Refer to strategy, for the last two thousand years the art of war had an enormous influence on military thinking, out of nothing" is a attacking stratagem in the famous "Thirtysix Stratagems", attributed to Sun Tzu (of The Art of War fame), in which strategies were divided into six categories, business tactics, legal strategy and beyond. "Create something namely "winning stratagems, enemy dealing stratagems, attacking stratagems. Chaos stratagems, proximate stratagems and defeat stratagems"[6]. The innovation mode of "create something out of nothing" has been a great boost to the tourism industry by breaking the traditional style and the similar geographical resources and mixing the exotic culture with local culture to form the distinctive design features. Lingshan Fangong Palace was boldly introduced the western dome structure and column and represented the culture of Dunhuang and Mandala with the extraordinary Chinese artworks, as shown in Fig.5.

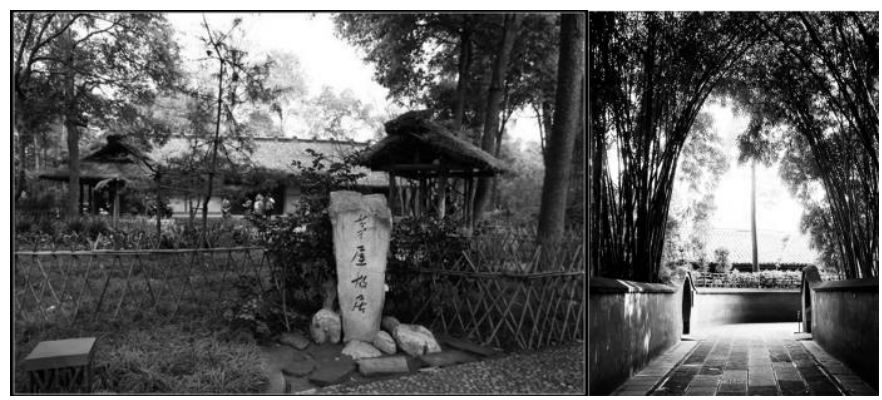

Fig.4. thatched cottage of Du Fu

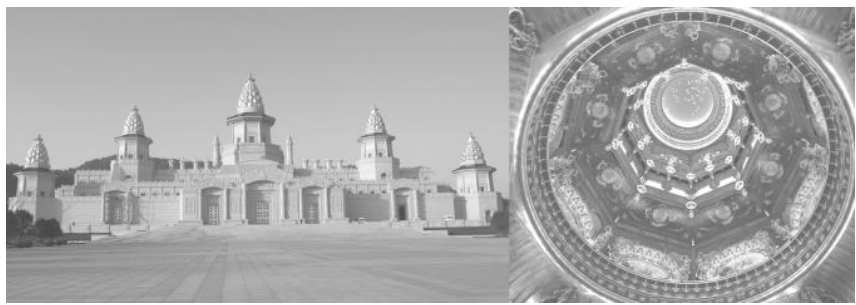

Fig.5. Lingshan Fangong Palaces

\section{E. The art of Zen}

Chinese metaphysical tradition constructs reality as a dynamic of interconnected events and entities in constant transformation[7]. As the essence of traditional culture, Zen has been positioned as an important methodological contribution of design aesthetic and philosophy, e.g. intuition and sudden enlightenment, simplicity and naturalness, vacant and tranquil beauty, unobtrusive and peaceful attitude. Consequently, Zen is widely used in the design of architecture, interior, furniture, household goods. Fig.6 shows a series of lovely product design with Zen theme. Furthermore, UX(user experience) is concerning with establishing the Kansei and unconscious approach, closely related to the heart-mind and personal expression of insight in Zen. The art of Zen aims to explore the real Chinese design based on truth, beauty, unselfconscious, and delicate thought by means of inserting Zen-meditation and Zen-teachings into traditional design curriculum.

\section{CONSTRUCTION OF THE FIVE MODULES}

According to the above description it is not difficult to find as an important element of Chinese quality-oriented education, the five design educational modules on sinology contribute to set up a framework of the training for the design qualities of 
sense, representability, emotion, wisdom and insight respectively, as shown in Fig.7.

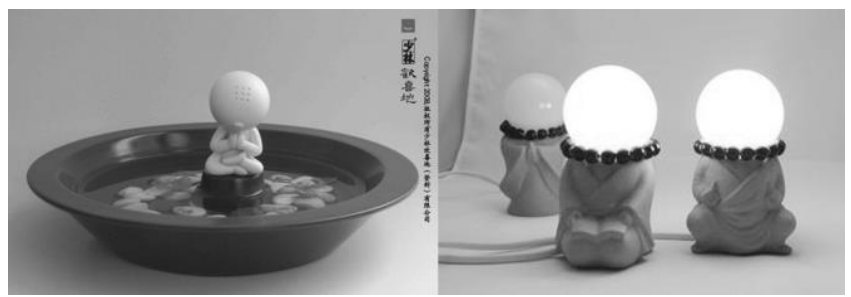

Fig.6. "budongxin"cultural household goods design of Shaolin monk theme

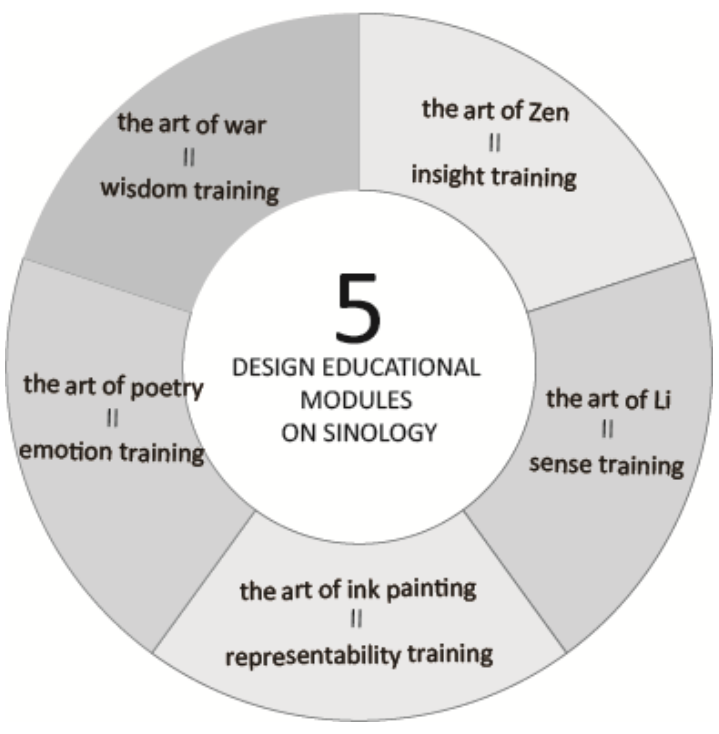

Fig.7. the quality training based on the five modules on sinlogy

The theory building will be strengthened empirically and pragmatically by more systematic construction proposals and curriculum plans as follows[8]:

- Strongly recommend to set up a specialized course of sinology for design, involved in the five modules. In accordance with the different universities disciplinary development, integrating the five modules with a specific course or 1 course corresponding to 1 module will be available to flexible curriculum construction.

- The curriculum construction of each module will consist of three program: (1) basic knowledge, involved in essential classics reading and life case analysis; (2) quality upgrading, a bridging between basic knowledge and design practice; (3) design practice, required to pragmatic design about sinology theme, details as shown in table. 1 .

- Encourage 5 minutes meditation before class and simple life.

- Build a special classroom or laboratory for Zenmeditation and ritual training of classic sacrificial ware.
China is gradually on the rise of meditation boom; Fig. 8 shows the meditation room of Lingshan Vihara in Wuxi with elegant and antique atmosphere in Chinese style.

- Set up MOOC platform.

- With the help of WeChat and its public ID it is plan to expand $\mathrm{O} 2 \mathrm{O}$ educational service and rich the online and outclass training.
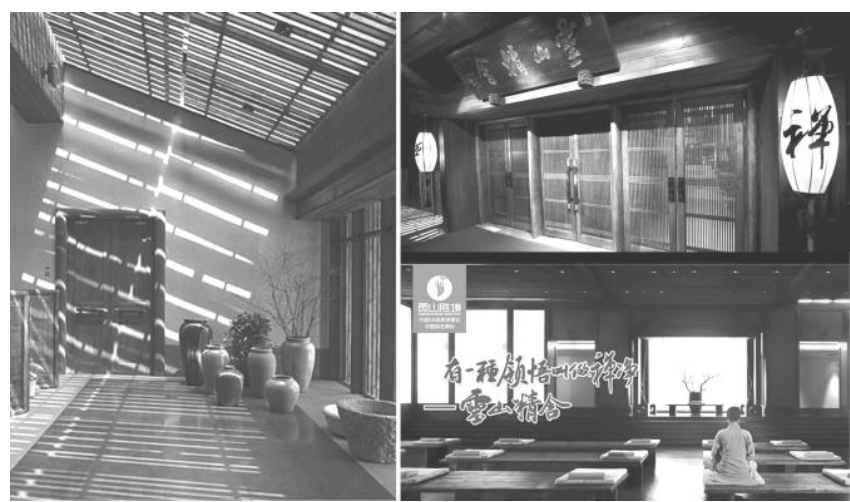

Fig.6. "budongxin"cultural household goods design of Shaolin monk theme

TABLE I. CURRICULUM CONSTRUCTION OF THE FIVE MOUDLES

\begin{tabular}{|c|c|c|}
\hline \multicolumn{3}{|c|}{ Curriculum Construction of the Five Modules } \\
\hline \multicolumn{3}{|c|}{ The Art of LI } \\
\hline Basic Knowledge & Quality Upgrading & Design Practice \\
\hline $\begin{array}{l}\text { Three Li } \\
\text { Rituals in classic } \\
\text { sacrificial ware } \\
\text { Rituals of everyday } \\
\text { things }\end{array}$ & $\begin{array}{l}\text { Living customs and design } \\
\text { psychology } \\
\text { Chinese intangible cultural } \\
\text { heritage research } \\
\text { UX(user experience) }\end{array}$ & $\begin{array}{l}\text { UX design } \\
\text { Gift design } \\
\text { Service design } \\
\text { Package design }\end{array}$ \\
\hline \multicolumn{3}{|c|}{ The Art of Ink Painting } \\
\hline Basic Knowledge & Quality Upgrading & Design Practice \\
\hline $\begin{array}{l}\text { Freehand brush } \\
\text { Painting }\end{array}$ & $\begin{array}{l}\text { Illustrator and story board } \\
\text { Blank and Layout design }\end{array}$ & $\begin{array}{l}\text { VI system design } \\
\text { Web design } \\
\text { Illustrator design }\end{array}$ \\
\hline \multicolumn{3}{|c|}{ The Art of Poetry } \\
\hline Basic Knowledge & Quality Upgrading & Design Practice \\
\hline $\begin{array}{l}\text { Tang Poetry and } \\
\text { Song Lyrics } \\
\text { Semiotics }\end{array}$ & $\begin{array}{l}\text { Emotional design } \\
\text { Design semantics } \\
\text { Aesthetic conception and } \\
\text { contextual design }\end{array}$ & $\begin{array}{l}\text { Architecture Design } \\
\text { Interior Design } \\
\text { Tourism industry }\end{array}$ \\
\hline \multicolumn{3}{|c|}{ The Art of War } \\
\hline Basic Knowledge & Quality Upgrading & Design Practice \\
\hline $\begin{array}{l}\text { Thirty-six } \\
\text { Stratagems }\end{array}$ & $\begin{array}{l}\text { Strategic Map } \\
\text { Paper Prototyping } \\
\text { Design Blueprint } \\
\text { PM(product management) }\end{array}$ & $\begin{array}{l}\text { Web design } \\
\text { APP design } \\
\text { Business innovation } \\
\text { Service design }\end{array}$ \\
\hline \multicolumn{3}{|c|}{ The Art of Zen } \\
\hline Basic Knowledge & Quality Upgrading & Design Practice \\
\hline $\begin{array}{l}\text { Zen-teachings } \\
\text { Zen garden }\end{array}$ & $\begin{array}{l}\text { Zen-Meditation } \\
\text { Simple life research }\end{array}$ & $\begin{array}{l}\text { Cultural and Creative } \\
\text { industrial design } \\
\text { Unconscious design }\end{array}$ \\
\hline
\end{tabular}

\section{CONCLUSIONS}

Modern Chinese design education should pay more attention to coordinate Chinese wisdom between sinology and 
design. The design education on sinology takes more emphasis on the spiritual exploration than the heritage of Chinese culture[9]. With the rapid development of information age, it is possible to become a new trend of design education as well as Confucianism and help to promote Chinese design to the international market.

\section{REFERENCES}

[1] Huang Yu-dong, "Chinese Classics and the Cultivation of University Students' Humanity Spirit,'Journal of Qinzhou University, vol. 4, pp. 125-126, 2011.

[2] Huo Hai-wei, "Present situation and countermeasures of sinology education for students in universities, " Journal of Agricultural University of Hebei(Agriculture and Forestry Education Edition), vol. 4, pp. 17-19, 2013.

[3] Wu Youxin, "Training thoughtful designers with an international perspective \& national identity-thoughts on the culture creative industry\& modern design education," Creation and Design, vol. 3, pp. 17-19,2010.

[4] Yang Peng, "The research of Cheng Ben-pu's study on Three Li" , Journal of Huaihua University,vol.1,pp.22-23, 2010.

[5] Wang Li-yuan, "The study of Chinese ink painting on layout design education", University Education, Vol.1, pp.59-60, 2012.

[6] Zhang Yong-shan, "The Thirty-six Stratagems and strategic education", Learning education, Vol.6, pp.120-121, 2015.

[7] Nan Qiao, Lijun Liu, "Zen view of Nature in the Performance of modern fashion design", Advanced Materials Research, Vol.331, pp.666-669, 2011.

[8] Yang Qichun, "On diversified design Education in an informationa age", Canadian Socal Science, Vol.10, pp.206-209, 2014.

[9] Benoit Vermander, "Chinese wisdom, management practices and the humanities", Journal of management development, Vol.30, pp.697-708, 2011. 